DOI 10.37882/2500-3682.2020.09.15

\title{
ОСОБЕННОСТИ КОММУНИКАЦИИ В МОЛОДЕЖНЫХ ВИРТУАЛЬНЫХ СООБЩЕСТВАХ
}

\section{PECULIARITIES OF COMMUNICATION IN YOUTH VIRTUAL COMMUNITIES}

\section{N. Senchenko}

Summary: The article deals with the features of communication in virtual communities. The author notes that immersion in the virtual world can be disastrous for minors. The article analyzes various virtual communities and general features of communication in them. The paper highlights the main characteristics of social networks: instability, hierarchy and the installation of expert authority. In addition, the author notes that the specifics of interaction are changing and the consideration of communicative activities in the Internet space should take place in parallel with progress, and change when new methods of communication appear on the Internet. The author analyzes the interaction in deviant communities.

Keywords: virtual community, social networks, deviation, youth and adolescents, communication.

\section{Введение}

C овременные интернет-коммуникации позволили человечеству не только сократить время получения информации, но и расширить возможности взаимодействия с другими людьми, невзирая на расстояние. В интернет-пространстве появляются новые площадки для общения людей - социальные сети, виртуальные сообщества, чаты, блоги. Виртуализация жизнедеятельности населения приводит к тому, что данная возрастная категория имеет несформированные навыки коммуникации в реальном пространстве, что делает виртуальное пространство еще желаннее.

Несовершеннолетние погружены в виртуальный мир, нередко, именно его воспринимая как реальный, но безопасный, игнорируя негативные примеры, приводимые взрослыми. Удовлетворение социальных потребностей в общении, игре, позитивном подкреплении [1-4] становится первостепенным для подростков и приводит подростков к поиску сообществ, где данные потребности будут удовлетворены в полной мере. При этом наиболее привлекательными для тинэйджеров становятся виртуальные субкультуры с девиантной направленностью в силу особенностей возраста и желания быть не такими как все.

Научная проблема исследования заключается в ана-
Сенченко Наталья Анатольевна

ГБОУ ВО РК «Крымский инженерно-педагогический университет имени Февзи Якубова», г. Симферополь senchenko_n.a@mail.ru

Аннотация: В статье идет речь об особенностях коммуникации в виртуальных сообществах. Автор отмечает, что для несовершеннолетних погружение в виртуальный мир может стать губительным. В статье анализируются различные виртуальные сообщества и общие особенности коммуникации В них. В работе отмечены основные характеристики социальных сетей: нестабильность, иерархичность и установку экспертной власти. Кроме того, автор отмечает, что изменяется специфика взаимодействия и рассмотрение коммуникативной деятельности в интернет-пространстве, должно проходить параллельно с прогрессом, и видоизменяться при появлении новых способов общения в интернете. Автором анализируется взаимодействие в сообществах девиантной направленности.

Ключевые слова: виртуальное сообщество, социальные сети, девиация, молодежь и подростки, коммуникация.

лизе особенностей коммуникации подростков и молодежи в молодежных виртуальных сообществах для создания системы превентивных мер против пагубного воздействия этих субкультур на личность.

Цель статьи - описание специфики общения в виртуальных сообществах.

\section{Основное изложение материала}

Прежде всего определимся с факторами привлекательности виртуальных сообществ и коммуникации в интернет-пространстве.

Так, в исследованиях А.И. Лучинкиной были выделены следующие характеристики: полифоничность как реакция одновременно на группу сообщений и создание комплексного ответа; поликультурность как возможность одновременного общения большого количества представителей различных культур и субкультур; гипертекстовость и интерактивность; анонимность и дистанциированность; добровольность и желательность контактов; заместительный характер общения [7].

В исследованиях других ученых отмечается возможность найти собеседников в любой точке мира; комфортность нахождения в знакомом пространстве; доступность к информации о личности партнера; обратимость 


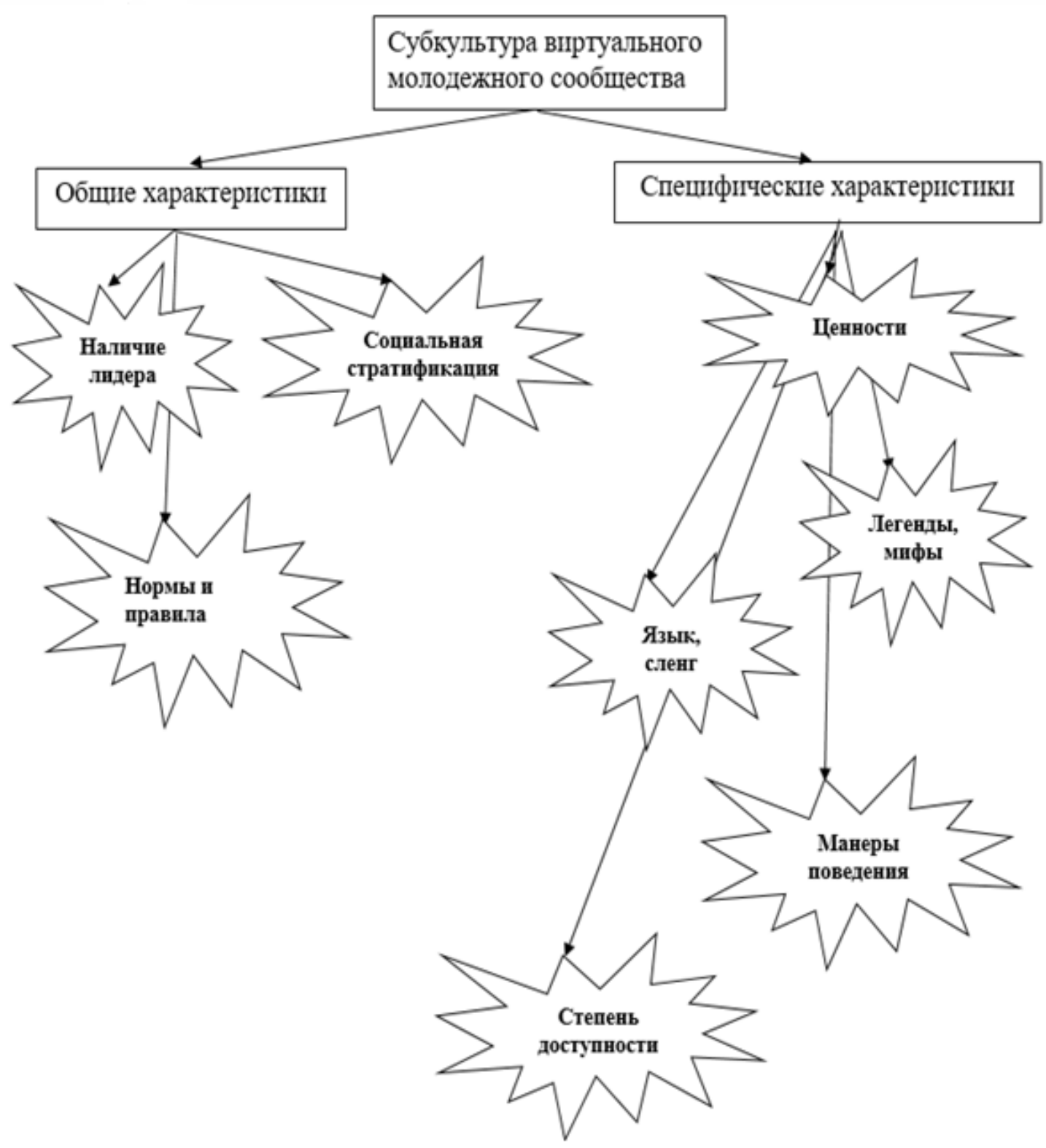

Рис. 1. Субкультура виртуального молодежного сообщества

времени $[2,4,10,14,15,16]$.

Следует отметить, что исследователи выделяют в качестве основных причин обращения молодежи в виртуальные сообщества, в том числе девиантной направленности, следующие: разочарование в реальном мире, невозможность найти свою референтную группу, неудовлетворенные потребности в позитивной оценке и самооценке, самореализации, проблемы с налаживанием общения в реальном пространстве $[7,11,12,15]$.

Особенностью интернет-коммуникации является инкультурация пользователя, принятие им норм и правил жизни в виртуальном сообществе, присоединение к сленгу, перенос акцентов на графические символы.
Одним из важных аспектов, способствующих инкультурации личности в виртуальном пространстве, ученые считают субъектность интернет-пользователя [9], приводящую к обмену идентичностями.

Кроме того, исследования коммуникаций в виртуальных сообществах выявили такие особенности, как затруднение эмоционального компонента, стремление к нетипичному, ненормативному поведению, являющейся презентацией себя с иной стороны, чем в условиях реальной социальной нормы, и проигрывание нереализуемых в внесетевой деятельности роли, либо сценарии ненормативного поведения [8].

Опираясь на типы культур, выделенные Маргарет 
Мид, обозначим культуру интернет-сообществ, как префигуративную, с учетом того, что современная молодежь быстрее осваивает интернет-технологии, но имеет меньший социальный опыт, чем более взрослое поколение [9]. Именно в связи со сказанным, подростки и молодежь быстрее, чем взрослые погружаются в интернетпространство и осваивают его культурное поле с риском для общепринятой культуры.

Вследствие расширения жизненного пространства личности от реальности в виртуальность осуществляется перенос имеющихся или рождение новых субкультур в виртуальном пространстве как менее освоенном людьми. При этом виртуальные субкультуры обладают всеми характеристиками реальных и являются материалистическим доказательством реальности жизни в виртуальном сообществе.

Если виртуальное сообщество, по мнению ученых (Р. Рейнгольд, М. Макклюэн) [13] представляет собой большое количество людей, лично вовлечённых в процесс общения по принципу обратной связи, связанных с существующим культурным контекстом и не зависящих от реальных прототипов[13]. По мнению исследователей, основными отличиями виртуальных сообществ от реальных являются отсутствие пространственно-временных ограничений и свобода выбора идентичности.

Кроме того, ученые в качестве основных общих характеристик следующие: наличие модераторов (админов), наличие структуры, свод норм и правил. При этом в качестве специфических характеристик могут выступать собственные правила, наличие групповых мифов, легенд, сленга, отсутствие территориальной приближенности.

Субкультура, по мнению исследователей, представляет собой отличающуюся от общепринятой часть культуры, имеющую свои ценности, языки, манеры поведения $[3,5]$.

Таким образом, между виртуальным сообществом и субкультурой существует явное сходство. Так, любое виртуальное сообщество имеет свою систему ценностей, свой язык, свою иерархию (организацию) и даже социальную стратификацию[6,7,8].

Многие исследователи отмечают короткий срок жизни виртуальных сообществ, зачастую это 2-3 года, при этом более долговечные сообщества отмечаются лишь как исключения [8].

При этом виртуальная субкультура может быть рассмотрена в широком и узком смысле слова. В широком смысле как виртуальная культура в целом. В узком - как часть виртуальной культуры, имеющая общие с нею ха- рактеристики, но обладающая собственной спецификой (рис.1).

В нашем исследовании мы исходим из определения виртуальной субкультуры в узком смысле слова.

Как видно на рисунке 1, все виртуальные субкультуры имеют общие и специфические характеристики. В качестве примера рассмотрим виртуальное сообщество «Смерть». Количество подписчиков - 125198 человек. Аудитория молодежная. В сообществе прослеживаются типичные для всех виртуальных объединений характеристики - наличие модераторов. Следует отметить, что о существовании модератора или администратора группы можно узнать только из косвенных сообщений в общем контента: «Админу на гроб!»; «Админ ожил!».

Социальная стратификация в сообществе не выражена явно и проявляется в количестве «лайков» и длине сообщений в темах. Наблюдается дифференциация членов сообщества по репутации, количеству постов и комментариев. При этом репутация напрямую связана с количеством «лайков», что придает общению конкурентный характер. Анализ доступного группового контента позволил определить группы экспертов, к чьим мнениям прислушивается большое количество членов сообщества.

Е.П. Белинская отмечает, что виртуальные сообщества обладают всеми характеристиками социальной организации, в том числе и открытостью, свободой, отсутствием границ [1]. Однако, зачастую это не так. Модераторы чаще всего ограничивают эту свободу в сети, путем оказания влияния на членов группы, наказания девиантного поведения. Обычно нарушителей исключают из группы, отправляют в «бан».

Нормы и правила группы прописаны в легенде группы.

От стандартного общения в социальных сетях общение данной группы отличается высоким интересом к теме смерти, что при таком большом количестве участников переводит сообщество в группу риска. По сути, мы имеем дело с субкультурой смерти.

Собственно, с этого и начинаются специфические характеристики данной субкультуры. Легенда данной группы включает в себя нормы и правила субкультуры (рис.2)

Основными ценностями данного сообщества являются ценности смерти. Весь контент направлен на декларацию этих ценностей (рис.3). Сообщения другой направленности не становятся популярными и не всегда пропускаются администратором группы. 


\section{= Данная пуб́личная страница НЕ предназначена для призыва к суициду и}

распространения национальной, расовой, религиозной, политической или

какой-либо Аругой неприязни. Пуб́ликации НЕ несут под собой цели

оскорбить чьи-то религиозные, атеистические, философские или какие-либо

аругие чувства.

Группа несёт исключительно развлекательный характер.

Рис. 2. Легенда сообщества

смерть

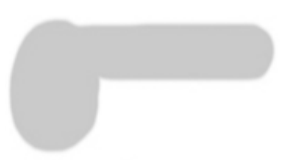

Спасибо тем, кто советовал лечить депрессию насыщенным графиком, теперь мне хочется умереть ещё сильнее, просто у меня нет на это времени

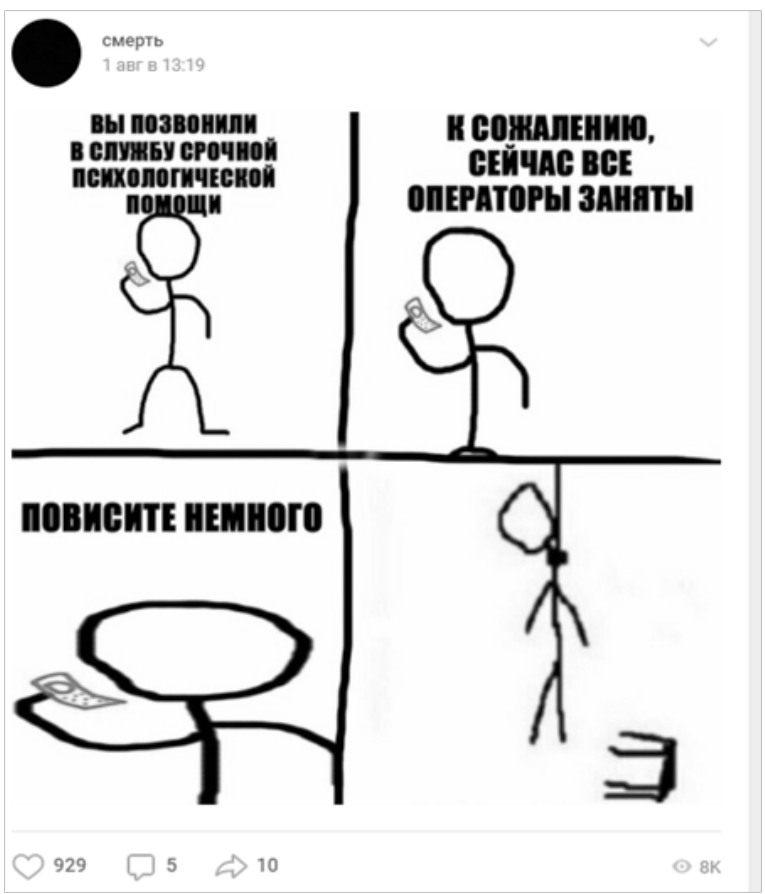

Рис. 3. Ценности группы

Частота употребления отдельных слов в сообществе

\begin{tabular}{|c|c|c|c|}
\hline Слово & $\begin{array}{c}\text { Частота употребления, в абсолют- } \\
\text { ных единицах }\end{array}$ & $\begin{array}{c}\text { Частота употребления, в абсолют- } \\
\text { ных единицах }\end{array}$ \\
\hline Смерть & 987 & Захоронение & 206 \\
\hline Гроб & 791 & Петля & 126 \\
\hline Депрессия & 412 & Время & 111 \\
\hline Сдохнуть & 312 & Повеситься & 49 \\
\hline Суицид & 309 & Яд & 34 \\
\hline
\end{tabular}


Как видно на рисунке 3, сообщения суицидальной направленности имеют большое количество просмотров и одобрений.

Следует отметить, что негласным правилом хорошего тона данной группы является иронизация смерти. Контент анализ 1000 сообщений на стене сообщества в социальной сети «ВКонтакте» позволил выделить частоту употреблений отдельных слов (см. табл.1).

Как видно по данным, приведенным в таблице 1, язык данного сообщества изобилует «смертоносными» терминами, что существенно отличает его от языков других сообществ.

По степени доступности - открытая группа, что лишает ее некоторой элитарности, свойственной другим молодежным субкультурам.

Данное сообщество создано в июле 2018 года на фоне блокирования контента «групп смерти». Следует отметить, что динамика присоединения к сообществу позитивная и в настоящий момент. При этом, мы отмечаем нестабильность самих сообществ как одну из их особенностей.

Следует отметить, что в сетевом общении визуальный и телесный контакт уходят на второй план, уступая тексту, что приводит к утомляемости коммуникаторов и их истощаемости. При этом анонимность становится скорее мечтой, чем реальностью. Приватность реальной жизни растворяется в виртуальных сообществах, отражаясь в личных комплексах и проблемах, выносимых на обсуждение широкой аудитории.

Таким образом, виртуальное сообщество отличается от других форм виртуальной коммуникации прежде всего осознанием наличием общих ценностей и целей, регулярностью участия пользователями в жизни сообществ, путем обратной связи и общения между собой.

ЛИТЕРАТУРА

1. Белинская Е.П. К проблеме групповой динамики сетевого сообщества //2-ая Российская конференция по экологической психологии. Тезисы. - М.: Экопсицентр РОСС, 2000. - С. 249-251.

2. Кремлева С.0. Сетевые сообщества [Электронный ресурс] / Электронный режим доступа: http://www.follow.ru/article/116 - (дата обращения: 17.11.2017).

3. руталевич, А.Н. Структурно-аналитический подход к изучению субкультур / А.Н. Круталевич // Культура и искусство. - 2016. - №1 (31). - С. 41-45.

4. Куликов Д.В. Феномен сетевого сообщества [Электронный ресурс] / Д.В. Куликов. - Электронный режим доступа: http://vio.uchim.info/Vio_35/cd_site/ articles/art_2_1.htm - (дата обращения: 17.11.2017).

5. Левикова С.И Молодежная субкультура: Учебное пособие / С.И. Левикова. - М.: ФАИР-ПРЕСС, 2004. - 608 с.

6. Лучинкина А.И. Методологические проблемы исследования коммуникативного поведения пользователей в интернет-пространстве / А.И. Лучинкина, И.С. Лучинкина. - Гуманитарные науки. - Ялта, 2017. - № 4. - С. 42.

7. Лучинкина А.И. Психологические закономерности социализации личности в виртуальном пространстве [Электронный ресурс] / А.И. Лучинкина. Электронный режим доступа: https://psy.su/psyche/projects/1416/ - (дата обращения: 22.02.2018).

8. Лучинкина И.С. Особенности коммуникативного поведения в интернет-пространстве подростков с разными типами суицидального поведения / А.И. Лучинкина, И.С. Лучинкина. - Российский психологический журнал. - 2019. - Т. 16. - № 1. - С. 128-143.

9. Мид М. Культура и мир детства / М.Мид. - М.: 1998. - С. 88-171; 322-362.

10. Мясников М.Л. Трансформация социальной среды: понятие сетевого сообщества / М.Л. Мясникова, В.Л. Мясникова. // Культура и взрыв: социальные смыслы в трансформирующемся обществе. $-2013-$ С. 268-273.

11. Плешаков В.А. Киберсоциализация как инновационный социально-педагогический феномен [Электронный ресурс] / В.А. Плешаков. - Электронный режим доступа: http://sirdionis.ucoz.ru/load/prezentacija_po_teme_kibersocializacija/ - (дата обращения: 17.11.2017).

12. Ратунова Л. Личность и виртуальная социализация [Электронный ресурс] / Л. Ратунова. - Электронный режим доступа: http://wiki.iteach.ru/index. php (дата обращения: 4.09.2017).

13. Рейнгольд Г. Умная толпа: новая социальная революция / Говард Рейнгольд. - Пер. с англ. А. Гарькавого. - М.: ФАИР ПРЕСС, 2006. - 416 с.

14. Репкин Д. Виртуальная реальность [Электронный ресурс] / Д. Репкин - Электронный режим доступа: http://www.virtual.ru/virtual_reality.html - (дата обращения: 4.09.2017).

15. Скуратов А.Б. Локальные интернет-сообщества крупного российского города: социально-стратификационный анализ / А.Б. Скуратов // Автореф. дис. на соискание ученой степени кандидата социологических наук. - 22.00.04 - социальная структура, социальные институты и процессы. - Екатеринбург, 2009. $-21 \mathrm{c}$.

16. Социальные сети и виртуальные сетевые сообщества: Сб. науч. тр. / РАН. ИНИОН. Центр социал. науч.-информ. исслед. Отв. ред. Верченов Л.Н., Ефременко Д.В., Тищенко В.И. - М., 2013. - 360 с. 